\title{
Update Breast Cancer 2019 Part 1 - Implementation of Study Results of Novel Study Designs in Clinical Practice in Patients with Early Breast Cancer
}

\section{Update Mammakarzinom 2019 Teil 1 - Implementierung der Ergebnisse neuer Studienkonzepte beim frühen Mammakarzinom in die klinische Praxis}

\section{(우(1) (옹}

Authors

Andreas D. Hartkopf ${ }^{1}$, Volkmar Müller ${ }^{2}$, Achim Wöckel ${ }^{3}$, Michael P. Lux ${ }^{4}$, Wolfgang Janni ${ }^{5}$, Naiba Nabieva ${ }^{4}$,

Florin-Andrei Taran ${ }^{1}$, Johannes Ettl ${ }^{6}$, Diana Lüftner ${ }^{7}$, Erik Belleville ${ }^{8}$, Florian Schütz ${ }^{9}$, Peter A. Fasching ${ }^{4}$, Tanja N. Fehm ${ }^{10}$, Hans-Christian Kolberg ${ }^{11}$, Friedrich Overkamp ${ }^{12}$, Andreas Schneeweiss ${ }^{13}$, Hans Tesch $^{14}$

Affiliations

1 Department of Obstetrics and Gynecology, University of Tübingen, Tübingen, Germany

2 Department of Gynecology, Hamburg-Eppendorf University Medical Center, Hamburg, Germany

3 Department of Gynecology and Obstetrics, University Hospital Würzburg, Würzburg, Germany

4 Erlangen University Hospital, Department of Gynecology and Obstetrics, Comprehensive Cancer Center ErlangenEMN, Friedrich-Alexander University Erlangen-Nuremberg, Erlangen, Germany

5 Department of Gynecology and Obstetrics, Ulm University Hospital, Ulm, Germany

6 Department of Obstetrics and Gynecology, Klinikum rechts der Isar, Technical University of Munich, Munich, Germany

7 Charité University Hospital, Campus Benjamin Franklin, Department of Hematology, Oncology and Tumour Immunology, Berlin, Germany

8 ClinSol GmbH \& Co. KG, Würzburg, Germany 9 Department of Obstetrics and Gynecology, University of Heidelberg, Heidelberg, Germany

10 Department of Gynecology and Obstetrics, University Hospital Düsseldorf, Düsseldorf, Germany

11 Department of Gynecology and Obstetrics, Marienhospital Bottrop, Bottrop, Germany

12 OncoConsult Hamburg GmbH, Hamburg, Germany

13 National Center for Tumor Diseases, Division Gynecologic Oncology, University Hospital Heidelberg, Heidelberg, Germany

14 Oncology Practice at Bethanien Hospital Frankfurt, Frankfurt, Germany
Key words

early breast cancer, adjuvant therapy, neoadjuvant therapy, T-DM1, Katherine, prevention

Schlüsselwörter

frühes Mammakarzinom, adjuvante Therapie, neoadjuvante Therapie, T-DM1, Katherine, Prävention

received $\quad 13.1 .2019$

accepted 28.1.2019

Bibliography

DOI https://doi.org/10.1055/a-0842-6614

Geburtsh Frauenheilk 2019; 79: 256-267 @ Georg Thieme

Verlag KG Stuttgart · New York | ISSN 0016-5751

Correspondence

Peter A. Fasching, MD

Erlangen University Hospital, Department of Gynecology and Obstetrics, Comprehensive Cancer Center Erlangen EMN, Friedrich Alexander University of Erlangen-Nuremberg Universitätsstraße 21-23, 91054 Erlangen, Germany peter.fasching@uk-erlangen.de

丹 Deutsche Version unter:

https://doi.org/10.1055/a-0842-6614

\section{ABSTRACT}

For many years, small but significant advancements have been made time and again in the prevention and treatment of early breast cancer. The so-called panel gene analyses are becoming more and more important in prevention, since the risk due to the tested genes is better understood and as a result, concepts for integration in health care can be developed. In the adjuvant situation, the first study in the so-called post- 
neoadjuvant situation was able to demonstrate a clear improvement in the prognosis with an absent pathological complete remission following trastuzumab or pertuzumab + trastuzumab. Additional studies with this post-neoadjuvant therapeutic concept are still being conducted at present. The CDK4/6 inhibitors which had shown a significant improvement in progression-free survival in a metastatic situation are currently being tested in the adjuvant situation in large therapeutic studies. These and other new data for the treatment or prevention of primary breast cancer are presented in this review against the backdrop of current studies.

\section{ZUSAMMENFASSUNG}

In der Prävention und Behandlung des frühen Mammakarzinoms sind über die Jahre immer wieder kleine, aber bedeutsame Fortschritte gemacht worden. In der Prävention gewinnen die sogenannten Panel-Gen-Analysen immer mehr an Be- deutung, da das durch die getesteten Gene bedingte Risiko immer besser verstanden wird und somit Konzepte für die Integration in die Krankenversorgung erarbeitet werden können. In der adjuvanten Situation konnte die erste Studie in der sogenannten postneoadjuvanten Situation bei fehlender pathologischer Komplettremission nach Trastuzumab oder Pertuzumab + Trastuzumab eine deutliche Verbesserung der Prognose zeigen. Weitere Studien mit diesem postneoadjuvanten Therapiekonzept werden zurzeit noch durchgeführt. Die CDK4/6-Inhibitoren, die in der metastasierten Situation eine deutliche Verbesserung des progressionsfreien Überlebens gezeigt hatten, werden zurzeit in der adjuvanten Situation in großen Therapiestudien getestet. Diese und weitere neue Daten zur Behandlung oder Prävention des primären Mammakarzinoms werden in dieser Übersichtsarbeit vor dem Hintergrund aktueller Studien vorgestellt.

\section{Introduction}

The prognosis of primary early breast cancer has continued to improve in the past few decades. This is seen in the improvement in the 5-year survival as well as in the increase in the rates of pathological complete remission ( $\mathrm{PCR}$ ) within the scope of neoadjuvant therapy concepts [1,2]. This suggests that not only optimisation of local therapy or early detection $[3,4]$ improved prognosis but also systemic therapy. The introduction of new substances and therapeutic regimens was able to improve therapy in the (neo)adjuvant situation little by little [5-7]. The choice of patient population appears to play an ever more important role here. For example, some years ago, so-called post-neoadjuvant studies were initiated which continued to treat patients who had not reached complete remission following neoadjuvant therapy. This type of study in particular appears to play an important role nonetheless, because they investigate a specific resistance population. This therapy concept but also aspects of prevention, surgical treatment, radiation therapy and other treatment strategies are discussed in this review.

\section{Prevention and Risk Factors}

Nearly 25 years after the discovery of BRCA1 and BRCA2, the techniques for genotyping have developed considerably further while the costs have decreased. Nowadays, when testing for risk genes in the genome, it is no longer only BRCA1 and BRCA2 which are genotyped, but rather a number of other genes which also influence the breast cancer risk. These are generally other genes which, in the case of a mutation, are also associated either with a disease risk similarly high as that of BRCA1 or BRCA2 or those genes which lead to a moderate disease risk [8-10].

Various works have reported on the mutation frequencies or risks in comparison to healthy control persons [11-17]. One of the genes which was discussed as being classified either in the high-risk group (similar to BRCA1 and BRCA2) or in the group with a medium disease risk is PALB2 $[11,12]$. Initial studies had esti- mated the lifetime risk between 35 and 55\% [11,18]. Another large study which analysed the extensive panel gene analyses on approx. 20000 cases of breast cancer and 20000 health control persons has now been published [19]. This study describes the relative risks for $B R C A 1$ and $B R C A 2$ with values of 7.9 and 6.7 and shows a relative risk of 4.8 for PALB2. Other genes identified with statistical significance were CHEK2 and ATM with relative risks of 2.5 and 1.7. If the cases were limited to the triple-negative patients, odds ratios of approx. 40 for BRCA1, approx. 14 for PALB2 and approx. 9 for BRCA2 [19] were seen. In clinical practice, lifetime risks are more helpful than relative risks. The corresponding lifetime risks were calculated at $50-55 \%$ for BRCA1 and BRCA2. PALB2 followed at slightly below $35 \%$. CHEK2 and ATM were below this figure, at 25 and 15\% [19]. The lifetime risks appear to be high enough in order to discuss individual risk-reducing measures, however they are not the only genetic factors known to increase the risk of breast cancer. The high-grade and medium-grade penetrant risk genes explain about $20 \%$ of the familial risk for breast cancer, while low penetrant but frequent genetic variants in over 170 loci explain a further $16 \%$ of the familial breast cancer risk [ 8 , $20-27$ ]. In order to also possibly harness these low penetrant risk variants for an individual risk determination, a risk score with 77 gene loci has already been previously developed [28]. This has now been supplemented with additional risk genes and redeveloped with 313 gene loci. Women in the highest percentile had a lifetime risk of approx. 33\% ( $\bullet$ Fig. 1) which can by all means be relevant for individual counselling [29]. For women around 60 years of age, a 10 -year disease risk of more than $10 \%$ can be calculated [29]. As in the case of all risk calculations, the identification of women with a risk for breast cancer with a poor prognosis is important. It was shown here that the polygenetic risk score in particular predicted the risk for hormone-receptor-positive carcinomas. While the lifetime risk for hormone-receptor-positive carcinomas could be calculated at over $30 \%$, the corresponding lifetime risk for hormone-receptor-negative carcinomas was approx. $4 \%$ [29]. The genes which account for a subtype-specific risk 
are known in part [15, 22, 30 - 39] and are of particular interest for the development of individualised preventive measures.

The additional combination with other risk factors could entail a further improvement in the risk prediction, since it is known that non-genetic risk factors have subtype-specific effects on the risk [40] and the polygenetic risk score either interacts with other risk factors or non-genetic risk factors improve the risk prediction in addition to the risk score [41-43].

\section{Surgical Treatment}

This year, a panel of experts published a needs assessment which identified the fields in which a special focus should be scientifically placed in the area of breast surgery in the near future. The important objectives of the further development are shown in $>$ Table 1: A roadmap for research needs in breast surgery at the current time [44]. For some of the issues raised in the report, there were interesting findings this year on which future research approaches can be built.

Between 2006 and 2016, the Young Women's Breast Cancer Study [45] which was conducted in the USA, included a total of 1302 women under age 40 with invasive breast cancer, 317 of whom received neoadjuvant therapy. Pretherapeutically, only 85 patients (27\%) were judged to be candidates for breast-conserving therapy. Posttherapeutically, this figure increased to 163

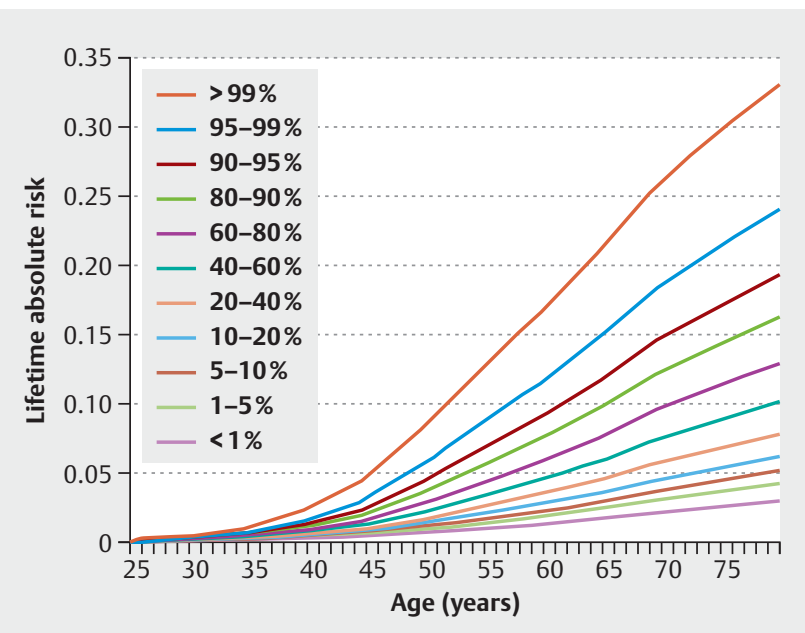

- Fig. 1 Cumulative lifetime risk for healthy women, as a function of a polygenic risk score with 313 gene loci (from [29]). The percentiles of the risk score and the lifetime risk based on them are shown.

(51\%). Only 80 of these patients (49\%) opted for breast-conserving therapy, 83 (51\%) chose mastectomy. The two most important reasons for a mastectomy were patient preference $(46 \%)$

- Table 1 Important objectives on the further development of breast surgery (acc. to [44]).

\begin{tabular}{|c|c|}
\hline Diagnosis and assessment & Neoadjuvant therapy \\
\hline $\begin{array}{l}\text { - Addressing overdiagnosis and } \\
\text { overtreatment, particularly in } \\
\text { the context of screening } \\
\text { - Understanding the biology, } \\
\text { importance, and long-term } \\
\text { outcomes of intermediate (B3) } \\
\text { lesions and ductal carcinoma } \\
\text { in situ } \\
\text { - Understand the biological sig- } \\
\text { nificance and optimal thera- } \\
\text { peutic strategies for additional } \\
\text { foci of previously subclinical } \\
\text { disease detected with advanced } \\
\text { imaging techniques } \\
\text { - Finding the best model for } \\
\text { symptomatic assessment that } \\
\text { allows rapid, patient-centred, } \\
\text { and cost-effective evaluation, } \\
\text { while maintaining diagnostic } \\
\text { accuracy } \\
\text { - Establishing how and when to } \\
\text { stage for distant disease and } \\
\text { how best to monitor for relapse }\end{array}$ & $\begin{array}{l}\text { - Understanding which patients will } \\
\text { benefit most from treatment with neo- } \\
\text { adjuvant chemotherapy or endocrine } \\
\text { therapy, how this benefit differs by bio- } \\
\text { logical subtypes, and what biomarkers } \\
\text { can best guide decision making } \\
\text { (eg, through window-of-opportunity } \\
\text { studies) } \\
\text { - Identifying the optimal treatment } \\
\text { choice and sequencing } \\
\text { - Understanding the long-term out- } \\
\text { comes of neoadjuvant endocrine } \\
\text { therapy } \\
\text { - Identifying the optimal modalities (ra- } \\
\text { diological and biomarker) for monitor- } \\
\text { ing treatment response } \\
\text { - Optimising rates of breast conserving } \\
\text { surgery after neoadjuvant treatment } \\
\text { - Identifying whether surgery can be } \\
\text { safely omitted in patients who achieve a } \\
\text { pathological complete response (pCR), } \\
\text { and what imaging or biopsy methods } \\
\text { can reliably predict pCR } \\
\text { - Understanding the optimal manage- } \\
\text { ment of the axilla in patients under- } \\
\text { going neoadjuvant therapy, particularly } \\
\text { those who convert from node-positive } \\
\text { to node-negative disease during treat- } \\
\text { ment and the role of sentinel lymph } \\
\text { node biopsy after treatment }\end{array}$ \\
\hline
\end{tabular}

\section{Surgical management}

- Developing strategies to reduce the rates of re-excision for patients undergoing breast conserving surgery through developments in localisation techniques and intraoperative margin assessment methods

- Understanding the role of alternatives to surgical excision. Assessment of clinical and costeffectiveness of oncoplastic and reconstructive surgery using standardised measures and how this is affected by patient factors and adjuvant treatment, particularly adjuvant radiotherapy to the chest wall

- Robust evaluation of novel procedures and techniques using appropriate methodology, such as the IDEAL framework, and commitment of the surgical community to the concept of no innovation without evaluation

- Management of the axilla in patients with a positive sentinel lymph node biopsy

\section{Special groups}

- Defining and standardising indications for risk-reducing surgery and understanding the long-term outcomes of bilateral mastectomy for those who are considered at high risk

- Defining and standardising indications for contralateral mastectomy in those with previous cancer to optimise benefits and minimise harm

- Increased understanding of breast cancer and differing patient needs in specific groups, including patients younger than 40 years, older patients, men, and patients with pregnancy-associated breast cancer

- Further study of survivorship, including optimisation of follow-up, secondary prevention, and the role of surgery for treatment-related morbidity, such as lymphoedema

- Understanding the role of surgery for metastatic disease 
and/or a BRCA1/2 or TP53 mutation (37\%). Of the 75 patients (24\%) who achieved pCR, 48 (64\%) received a mastectomy and only 21 of them 21 (44\%) for anatomical reasons (inflammatory carcinoma, extensive intraductal components, etc.) [45]. These data show that, especially in young patients, the decision for or against a mastectomy after neoadjuvant therapy is often made more for personal and risk-reduction reasons than for strictly oncological reasons. Whether these results can be transferred to other care structures, such as in Germany, has not yet been investigated to date.

In this context, reference should be made to the results of two other studies, each with far more than 500 patients and which addressed with the long-term quality of life following breast cancer surgery: the E5103 study [46] which had included all age groups, and another large multicentre study which assessed quality of life $(\mathrm{QoL})$ in patients under age 40 [47]. In both investigations, the authors found indications that the long-term quality of life was negatively affected by the radical nature of the surgical approach. In particular in the investigation which had included patients under age 40 (range 26-40, mean age 37 years), the psychosocial and sexual well-being was significantly worse in the group of patients who underwent mastectomy [46, 47]. It is known from other studies that dissatisfaction with the outcome following a mastectomy without reconstruction persists for many years [48]. Such data must be continuously reviewed in light of modern and less traumatising reconstruction techniques; however, they should also be mentioned within the context of informed consent during preoperative counselling.

Several translational analyses of the SENTINA study [49] were presented this year on the question of management of the axilla following neoadjuvant chemotherapy. In one investigation, the post-therapeutic involvement of axillary lymph nodes in the case of affected sentinel lymph nodes prior to neoadjuvant therapy was analysed. 71 out of 318 patients (22.3\%) still had affected lymph nodes following neoadjuvant therapy, whereby patients with a positive HER2 status and a negative axillary status had the highest PCR rates of the breast [50]. In another analysis as well in which a normogram for the prediction of nodal conversion was developed for patients with pretherapeutically affected lymph nodes, the greatest predictive factor was the tumour biology [51]. These investigations make current concepts appear promising with regard to forgoing axillary surgery in studies on patients with an aggressive tumour biology and PCR in the breast in the case of post-therapeutic clinically unremarkable lymph nodes.

\section{Radiation Therapy}

\section{Management in the case of positive lymph node involvement}

The sentinel lymph node biopsy (SNB) is the standard in clinically unremarkable axillary lymph nodes. However, what should be done if these lymph nodes are affected by tumour? The ACOSOG0011 study showed that dispensing with a further axillary lymphadenectomy (ALND) does not lead to an increased rate of recurrence, although $23 \%$ of patients have other affected lymph nodes which remain in situ. The main critical points of the study were the low statistical power (discontinuation due to low recruitment) and the unclear irradiation fields at the axilla [52].

The main question of the AMAROS study $(n=1425)$ [53] was more clearly defined here: in the event of a positive SNB, should irradiation (AxRT) or surgery (ALND) be performed? After 10 years of follow-up, a very low rate of local recurrence in both arms was seen overall, although additional metastases were found in the surgical arm in $32.8 \%$ of patients. The rate of axillary recurrence was $1.82 \%$ in the AxRT arm and $0.93 \%$ in the ALND arm (HR 1.71; $95 \% \mathrm{Cl}: 0.67-4.39, \mathrm{p}=0.365)$. In DFS as well, there was no difference (HR 1.19; $95 \% \mathrm{Cl}$ : 0.97-1.45). However, the rate of lymphoedema requiring treatment was significantly higher in the ALND arm. $82 \%$ of the patients received breast-conserving surgery and $17 \%$ underwent mastectomy and thus the results for both collectives appear representatives with a very low event rate, however. Conclusion: If axilla is clinically unremarkable and despite affected sentinel lymph nodes, further surgery is not felt to be appropriate. Whether extensive (AMAROS) or tangential (ACOSOG0011) irradiation should be performed cannot be answered yet [53].

\section{Partial breast irradiation}

In radiation therapy as well, de-escalation is an important strategy for reducing therapy-related morbidity and/or the duration of treatment. Partial breast irradiation by means of interstitial brachytherapy, three-dimensional conformal external irradiation or intraoperative irradiation (e.g. Intrabeam ${ }^{\circledR}$ ) could contribute to this. Within the scope of the randomised phase III study NSABP B-39, which included a total of 4216 patients with primary breast cancer in stage I-III, the non-inferiority of partial breast irradiation versus conventional whole-breast irradiation was investigated [54]. All forms of partial breast irradiation were permitted. The ipsilateral rate of recurrence was selected as the primary endpoint of the study. The mean follow-up was 10.2 years. The non-inferiority unfortunately could not be demonstrated, even though the 10 -year rate of recurrence in the case of partial breast irradiation was only $0.7 \%$ higher ( 4.6 vs. $3.9 \%$ ). The recurrence-free interval in the case of partial breast irradiation was in fact significantly shorter (recurrence-free 10-year interval 91.8 vs. 93.4\%), however no difference was seen in the case of metastasis- and diseasefree survival or overall survival. The grade 3-5 rates of toxicity do not differ significantly. Thus for the low-risk patients, partial breast irradiation may represent an option due to the only slightly increased risk of recurrence versus whole-breast irradiation.

\section{Irradiation of the lymphatic vessels}

The indication for irradiation of the lymphatic drainage area (LDA) is based on the current guidelines and therapeutic recommendations for the involvement of more than three lymph nodes (LN), independent of the size of the tumour as well as high-risk constellations (1-3 LNs affected, G2-3, ER/PR negative) [55 - 57]. A current meta-analysis which altogether included data from 13500 patients from 14 studies, confirmed this approach [58]. While earlier studies from 1961-1978 showed a slightly improved breast cancer mortality $(-0.5 \%)$ and had an increased overall mortality, the more recent studies from 1989 and later demonstrated a significantly reduced breast cancer and overall mortality $(-2.8 \%$ and 
$-2.9 \%)$. This can most likely be attributed to precision radiation therapy which minimises the cardiac radiation exposure (below $8 \mathrm{~Gy})$. In the subgroup evaluation, patients with more than three affected LNs particularly benefited from irradiation of the LDA. Thus the meta-analysis confirms the currently recommended approach.

\section{Therapy for Primary Triple-Negative Breast Cancer}

The treatment of triple-negative breast cancer (TNBC) in the adjuvant or neoadjuvant situation is marked by the fact that chemotherapy demonstrates good efficacy in a portion of the patients and this results in a considerable improvement in the prognosis. Thus it was able to be shown in neoadjuvant studies that triplenegative patients who achieve PCR have an excellent prognosis, similarly to HER2-positive patients [59-66].

In the event of a lack of $\mathrm{pCR}$ following neoadjuvant chemotherapy, the CREATE-X study examined an adjuvant therapy with capecitabine in HER2-negative patients [67]. Particularly in the triple-negative patients, this study, which was conducted in Asia, showed an advantage for disease-free survival (DFS) with a hazard ratio of 0.59 (95\% Cl: 0.39-0.87) [68].

The CIBOMA/2004-01_GEICAM/2003-11 study was conducted in a different study setting but with the same question regarding modified therapy [69]. This study, which was conducted in Spain and Latin America, admitted triple-negative patients following adjuvant or neoadjuvant chemotherapy who received further treatment after completing therapy with capecitabine or who did not receive any further therapy. As expected, the toxicity in the experimental arm was higher. In addition, no improved, recurrence-free survival could be observed (HR: 0.82 [95\% Cl: 0.63, 1.06], $\mathrm{p}=0.136$ ). A difference could be detected only in a subgroup with non-basal TNBC carcinomas (EGFR and CK5/6 negative) ( $p=0.020$, HR: 0.53 [95\% Cl: $0.31,0.91])$. However, since the study was negative overall, it was also concluded in the subsequent discussion that, outside of the conditions in the Create- $X$ study, the use of capecitabine is not indicated in patients with TNBC [69].

In some studies, the efficacy of gemcitabine, nab-paclitaxel and carboplatin in early breast cancer has already been investigated [70-81]. In summary, these studies showed that the addition of gemcitabine to standard therapy did not lead to any improvement and the latter yielded a benefit in a comparison between standard therapy and therapy containing platinum. In the ADAPT study, a higher pCR rate (26 vs. $45 \%$ ) in patients with therapy containing platinum could be found [82] in triple-negative patients following neoadjuvant chemotherapy in a comparison between treatment with nab-paclitaxel and gemcitabine vs. nabpaclitaxel and carboplatin [82]. With regard to disease-free survival (DFS), the study did not find any difference in the two treatment arms [83]. The question of possible predictive markers was posed in a recently presented analysis [84]. While patients with PCR and higher PD1 expression had the best prognosis, no predictive markers for the superiority of carboplatin in TNBC in neoadjuvant chemotherapy were able to be identified. In patients with
pCR after 12 weeks and a high baseline PD1 (mRNA), the postoperative continuation of chemotherapy with 4 cycles of epirubicin and cyclophosphamide did not lead to a better prognosis. However, the decision regarding continuation of the neoadjuvant therapy was not randomised. The authors evaluated this as an indication for a possible future basis for de-escalation, even if the results currently only generate hypotheses and cannot be assessed as the current basis for decision-making [84].

\section{Adjuvant Therapy of Primary, Hormone- Receptor-Positive, HER2-negative Breast}

\section{Cancer}

There are primarily three questions associated to date with the therapy of hormone-receptor-positive, HER2-negative breast cancer patient in the adjuvant situation: In which risk constellation must chemotherapy be administered? What is the optimal antiendocrine therapy? And how long should this be given?

With regard to the question of chemotherapy, it is known that patients with a positive hormone receptor status, particularly with low proliferation, do not respond well to chemotherapy $[60,62$, 85]. The question thus arises as to whether chemotherapy is of any use at all in such a patient population. The TAILOR-X study recently showed that patients who had achieved an intermediate score with regard to the risk of relapse in a multi-gen assay do not benefit from adjuvant chemotherapy followed by antihormonal therapy in comparison to antihormonal therapy alone [86]. Thus in this patient population, chemotherapy could be omitted. Newly presented quality-of-life data from the TAILOR-X study highlight this therapeutic decision approach [87] (further discussion in [88]).

In the question regarding the length of the adjuvant, antihormonal therapy with aromatase inhibitors, therapy until the 10th year after diagnosis is recommended to date in the guidelines and therapeutic recommendations more for patients with an increased risk of relapse than for patients with a low risk of relapse. The numbers of cases for such analyses were relatively small in the respective studies, however. The question also arises as to whether expanded adjuvant therapy with an aromatase inhibitor after tamoxifen brings as much benefit as after an aromatase inhibitor. These questions were addressed by a meta-analysis of the Early Breast Cancer Trialists Collaborative Group with more than 22000 patients from 11 studies [89].

The very comprehensive analyses investigated, on the one hand, the effect of aromatase inhibitors after 5 years of tamoxifen, after 5 years of aromatase inhibitors or after $5-10$ years of a sequence of tamoxifen and aromatase inhibitors. In addition, subgroup analyses were performed in the overall population for patients with $0,1-3$ and more than 3 affected lymph nodes. The therapeutic effect was the greatest in the group of patients who were pretreated only with tamoxifen and only marginal for patients who had received five years of pretherapy with aromatase inhibitors. The relative risks for all analyses are shown in $\mathbf{~ T a b l e ~} \mathbf{2}$.

In the analysis of the relative risks for a recurrence as a function of the node status, it was shown that the greatest effect could be 
- Table 2 Risk reductions of expanded antihormonal therapy with aromatase inhibitors (AI) after tamoxifen (TAM), Al or TAM, followed by AI (according to [89]).

\begin{tabular}{|c|c|c|c|c|c|c|c|}
\hline \multirow[t]{2}{*}{ Prior therapy } & \multirow[t]{2}{*}{$\mathbf{n}$} & \multicolumn{2}{|l|}{ Any relapse } & \multicolumn{2}{|c|}{ Distant metastases } & \multicolumn{2}{|c|}{ Breast cancer mortality } \\
\hline & & $\mathrm{RR}(95 \% \mathrm{Cl})$ & p value & $\mathrm{RR}(95 \% \mathrm{Cl})$ & p value & RR (95\% Cl) & $\mathrm{p}$ value \\
\hline 5 years TAM & 7483 & $0.67(0.57-0.79)$ & $<0.00001$ & $0.77(0.63-0.93)$ & 0.008 & $0.77(0.59-1.00)$ & 0.05 \\
\hline 5 years $\mathrm{Al}$ & 3322 & $0.76(0.61-0.95)$ & 0.2 & $0.78(0.59-1.04)$ & 0.09 & $0.99(0.68-1.44)$ & 0.97 \\
\hline $5-10$ years Tam, then $\mathrm{Al}$ & 11387 & $0.82(0.73-0.93)$ & 0.002 & $0.92(0.80-1.07)$ & 0.29 & $0.93(0.77-1.12)$ & 0.45 \\
\hline All patients & 22192 & $0.76(0.70-0.83)$ & $<0.00001$ & $0.85(0.77-0.95)$ & 0.004 & $0.89(0.77-1.02)$ & 0.09 \\
\hline Pat. with NO & 10620 & $0.82(0.71-0.95)$ & 0.009 & -1 & & -1 & \\
\hline Pat. with 1-3 LN & 6919 & $0.74(0.64-0.85)$ & 0.00003 & -1 & & -1 & \\
\hline Pat. with > $3 \mathrm{LN}$ & 1621 & $0.71(0.56-0.89)$ & 0.003 & -1 & & -1 & \\
\hline
\end{tabular}

seen in the population of patients who had more affected lymph nodes at primary diagnosis ( $\bullet$ Table 2 ) [89]. It is also important to note that the risk of bone fractures due to the expanded Al therapy was increased by $24 \%$ [89].

In a similar context, the AERAS study presented by Ohtani et al. is noteworthy: The expanded therapy with anastrozole for a total of 10 years in 840 patients reduced the DFS events by half in comparison to 843 patients whose endocrine therapy was ended after 5 years (HR 0.548, $p=0.0004$ ). No influence on overall survival was able to be shown. At the same time, the fracture rate of $2.8 \%$ in the expanded therapy arm was twice as high as in the control arm (1.1\%) [90].

Another option for intensifying the adjuvant endocrine therapy is to combine the endocrine therapy with substances which have already shown in a metastatic situation that they can overcome endocrine resistance in at least some patients. After the introduction of everolimus in the treatment of patients with metastatic breast cancer $[91,92]$, adjuvant studies were also subsequently started (e.g. NCT01674140, NCT01805271); they are still awaiting publication. Another option is the combination with CDK4/6 inhibitors which have a more favourable adverse effect profile. In this regard, there were recently meaningful results from the neoadjuvant therapy situation. Dowsett et al. presented the results from the Pallet study: In this study, palbociclib was given in addition to three months of neoadjuvant endocrine therapy with letrozole. It was shown that the antiproliferative effect of the aromatase inhibitor is substantially increased by palbociclib: The percentage of tumours which underwent a complete cell cycle arrest in the form of a Ki-67 value $<2.7 \%$ during neoadjuvant therapy was able to be increased through the addition of palbociclib from 58.5 to $90.4 \%$ [93].

With new, effective combination therapies, additional options are available which increasingly improve the adjuvant therapy of the hormone-receptor-positive, HER2-negative patient. At present, adjuvant therapy studies are being conducted for all CDK4/6 inhibitors (Penelope, PALLAS, MonarchE and NataLEE).

With the further development of adjuvant antihormonal therapy, the question of compliance arises, particularly in the case of an adverse effect profile known to be more unfavourable, and this question has already been discussed in the adjuvant studies with an antiendocrine monotherapy. Some studies have reported on adherence [94-98], which was between 60 and $90 \%$. It will be of interest to see how this is influenced by combination with a CDK4/ 6 inhibitor, particularly as it is known that adverse effects are one of the main predictors for non-adherence.

\section{Therapy of Primary HER2-positive Breast Cancer}

\section{Benefits of neoadjuvant therapy}

Neoadjuvant systemic therapy permits in-vivo sensitivity testing in addition to a reduction in surgical morbidity (more breast conservation, fewer axillary lymphadenectomies) $[99,100]$. Based on the effect of the neoadjuvant systemic therapy on the primary tumour, its effect on the long-term prognosis can be estimated, possibly through the destruction and monitoring of micrometastases [62,101].

A recent meta-analysis once again highlighted the prognostic significance of reaching pathological complete remission ( $p C R$ ) following neoadjuvant chemotherapy [102]. After evaluating 52 studies ( $51.1 \%$ randomised; $6.1 \%$ single-arm; $42.8 \%$ retrospective) with 27895 patients and a median follow-up period of 4 years, it was confirmed that, by achieving PCR, the risk of a breast cancer event decreases significantly by $69 \%$ (HR $0.31 ; 95 \%$ $\mathrm{Cl} 0.24-0.39$ ) and the risk of dying decreases significantly by $78 \%$ (HR 0.22; 95\% Cl 0.15-1.30). The absolute effect after 5 years on DFS and overall survival (OS) was 21 and 19\%, respectively ( $\triangleright$ Fig. 2 and 3). With a short follow-up time, the absolute effect was the greatest in the case of patients with triple-negative breast cancer, followed by patients with HER2-positive and hormone-receptor-positive, HER2-negative breast cancer ( $\Delta$ in the 5-year EFS 33 vs. 23 vs. $9 \%$ ). According to the statistics, a $\Delta$ in the $\mathrm{PCR}$ rate of $20 \%$ transferred in the studies into a reduction in the event risk by approx. 20\% [102]. Additional postoperative chemotherapy after reaching $\mathrm{PCR}$ did not improve the prognosis. 


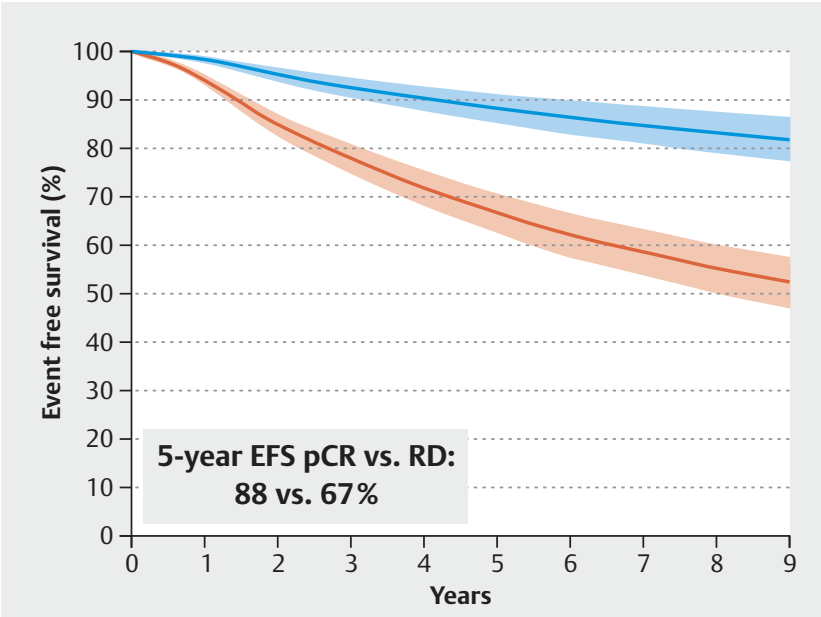

- Fig. 2 Event-free 5-year probability after neoadjuvant chemotherapy and with pathological complete remission (blue) or without PCR (red).

\section{Improvement in prognosis through a switch to T-DM1 in the case of non-pCR}

The phase III CREATE X study showed for the first time that, by adapting the postoperative therapy to the pathological response to the neoadjuvant therapy, the risk of recurrence and mortality can be significantly decreased [67]. While the CREATE X study included only patients with a HER2-negative breast cancer who did not achieve PCR through neoadjuvant chemotherapy, the KATHERINE study tested the same approach in patients with HER2positive breast cancer $[103,104]$. This study included 1486 patients with primary HER2-positive breast cancer who had not achieved PCR following neoadjuvant standard therapy with at least one taxane and trastuzumab for at least 9 weeks. The neoadjuvant therapy could include anthracyclines and a dual anti-HER2 blockade. The patients were randomised postoperatively and received either trastuzumab emtansine (T-DM1) $3.6 \mathrm{mg} / \mathrm{kg}$ or trastuzumab $6 \mathrm{mg} / \mathrm{kg}$ every 3 weeks for 14 cycles, at the same time as locoregional and, in the case of hormone receptor expression, endocrine standard therapy. Prospective stratification was performed according to operability (primarily operable vs. inoperable), hormone receptor status (positive vs. negative), type of neoadjuvant anti-HER2 therapy (trastuzumab vs. dual blockade with trastuzumab and pertuzumab) and the nodal status following surgery (ypN0 vs. ypN+). With a median follow-up period of 41 months, the switch to T-DM1 significantly improved the primary endpoint, the invasive disease-free survival after 3 years (IDFS), from 77.0 to $88.3 \%(\triangle 11.3 \%$; HR 0.50 ; $95 \%$ Cl $0.39-0.64$; $\mathrm{p}<0.0001)$ ( $\vee$ Fig. 4). The relative effect was the same in all stratified subgroups, particularly also in the case of patients with a very small residual tumour ( $\leq$ ypT1b ypN0) and in those who had neoadjuvantly received a dual anti-HER2 blockade. This also appears to be important to mention for this reason, because the neoadjuvant therapy with trastuzumab and pertuzumab, similar as in clinical studies, had also shown a higher pCR rate in real-world analyses [105]. The metastasis-free survival (distant disease-free sur-

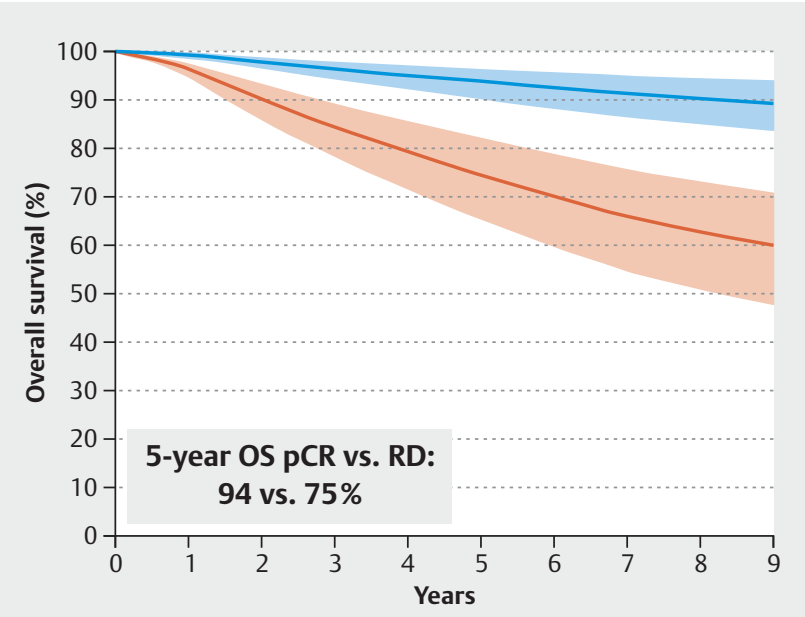

- Fig. 3 5-year overall probability after neoadjuvant chemotherapy and with pathological complete remission (blue) or without pCR (red).

vival, DDFS) after 3 years was also significantly improved from 83.0 to $89.7 \%$ ( $\Delta 6.7 \%$; HR $0.60 ; 95 \% \mathrm{Cl} 0.45-0.79)$. This benefit was achieved at the expense of a clinically easily controlled increase in thrombopenia (grade $\geq 3 \Delta 5.7 \%$ ), increased liver values (grade $\geq 3 \Delta$ approx. $1 \%$ ) and polyneuropathy (grade $\geq 3 \Delta 1.4 \%$ ) [103]. Thus the switch to T-DM1 in the case of non-pCR following adequate neoadjuvant systemic therapy in HER2-positive primary breast cancer represents a new therapeutic standard.

\section{Duration of the trastuzumab treatment}

In patients with HER2-positive, primary breast cancer who are indicated for treatment with trastuzumab, the question repeatedly arises as to whether a one-year treatment duration is absolutely necessary or whether shorter therapy can be considered [106]. In this context, the final survival data from the phase III PHARE study were recently presented [107]. In this non-inferiority study, 3384 patients with HER2-positive, primary breast cancer $(57.7 \%$ hormone-receptor-positive; $44.6 \%$ nodal-positive; approx. $43 \%$ trastuzumab therapy sequentially) who were still event-free after 6 months on trastuzumab randomly received either trastuzumab for another 6 months or no further anti-HER2 therapy. With a median follow-up time of 7.5 years, the DFS as well as the DDFS and OS after only 6 months of trastuzumab therapy were not clearly equally good as after one year of trastuzumab. The upper limit of the $95 \% \mathrm{Cl}$ of the HR was above the predefined maximum value of 1.15. However, in the subgroup in which trastuzumab was already started during chemotherapy, both therapy arms were equally effective. Nevertheless, the equivalence of 6 vs. 12 months of trastuzumab treatment could not be demonstrated with sufficient certainty overall and thus trastuzumab therapy for a year remains the standard. 


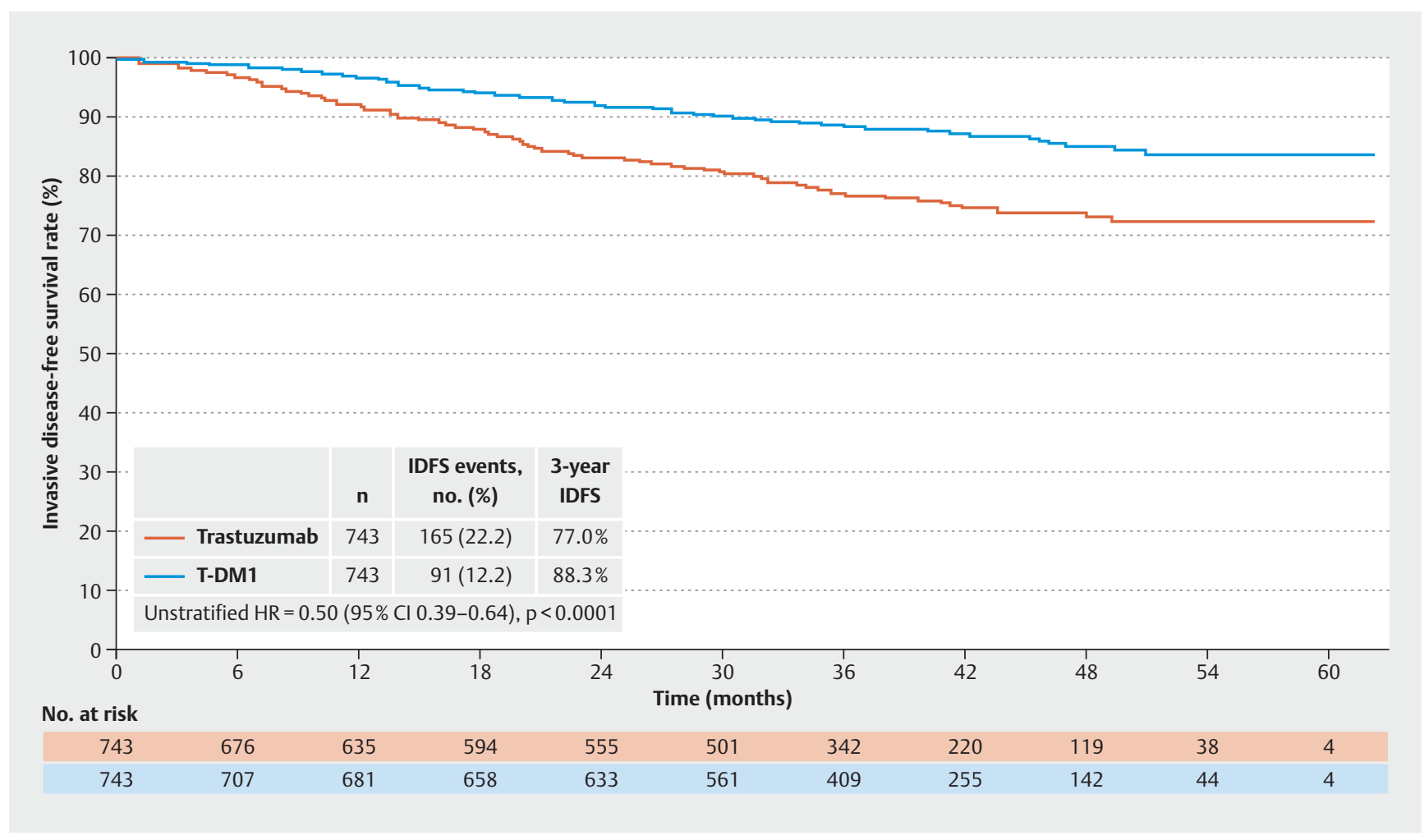

- Fig. 4 Invasive disease-free survival when comparing the two randomisation arms of the Katherine study (modified according to [104]).

\section{Outlook}

With the KATHERINE study, a large adjuvant study which can demonstrate a significant reduction in the risk of relapse for the HER2positive patient population treated neoadjuvantly was presented. This is significant not only for this patient group but also for patients with other tumour biologies. Patients with hormone-receptor-positive, HER2-negative breast cancer were treated in a similar, post-neoadjuvant therapy concept with palbociclib. The initial results are expected in mid-2019. The Olympia study also included post-neoadjuvant patients with a BRCA mutation for therapy with olaparib.

Independent of the post-neoadjuvant situation, three large adjuvant studies with CDK4/6 inhibitors which also have a potential for significant therapeutic efficacy are currently being conducted.

\section{Acknowledgements}

This work was developed in part as a result of support from Riemser and the PRAEGNANT network which is supported by Hexal, Pfizer, Celgene, Daiichi-Sankyo, Roche, Merrimack, Eisai, and Novartis. None of the companies played a role in the drafting of this manuscript. The authors alone are responsible for the content of the manuscript.

\section{Conflict of Interest}

A.D.H. received speaker and consultancy honoraria from AstraZeneca, Genomic Health, Roche, Novartis, Celgene, Lilly, MSD, Eisai, Teva, Tesaro, Daiichi-Sankyo, Hexal and Pfizer. N. N. received consultancy honoraria from Janssen-Cilag and Novartis. F. O. received speaker and consultancy honoraria from Amgen, AstraZeneca, Bayer, BMS, BoehringerIngelheim, Chugai, Celgene, Cellex, Eisai, Gilead, Hexal, Ipsen, JanssenCilag, Merck, MSD, Novartis, Riemser, Roche, Tesaro, Teva. F.-A.T. received honoraria from Astra Zeneca, Genomic Health and Novartis. H.-C. K. received honoraria from Carl Zeiss meditec, Teva, Theraclion, Novartis, Amgen, Astra Zeneca, Pfizer, Janssen-Cilag, GSK, LIV Pharma, Roche and Genomic Health. P. A. F. received honoraria from Novartis, Pfizer, Roche, Amgen, Celgene, Daiichi-Sankyo, AstraZeneca, MerckSharp \& Dohme, Eisai, Puma and Teva. His institution conducts research with funding from Novartis and Biontech. H. T. received honoraria from Novartis, Roche, Celgene, Teva, Pfizer and travel support from Roche, Celgene and Pfizer. J. E. received honoraria from Astra Zeneca, Roche, Celgene, Novartis, Lilly, Pfizer, Pierre Fabre, Teva and travel support from Celgene, Pfizer, Teva and Pierre Fabre. M.P. L. has participated on advisory boards for AstraZeneca, MSD, Novartis, Pfizer, Eisai, Genomic Health and Roche and has received honoraria for lectures from MSD, Lilly, Roche, Novartis, Pfizer, Genomic Health, AstraZeneca, medac and Eisai. V. M. received speaker honoraria from Amgen, Astra Zeneca, Celgene, Daiichi-Sankyo, Eisai, Pfizer, Novartis, Roche, Teva, Janssen-Cilag and consultancy honoraria from Genomic Health, Hexal, Roche, Pierre Fabre, Amgen, Novartis, MSD, Daiichi-Sankyo and Eisai, Lilly, Tesaro and Nektar. E. B. received honoraria from Novartis, Celgene, Riemser, Pfizer, Hexal, Amgen, and onkowissen.de for consulting, clinical research management or medical education activities. A.S. received honoraria from Roche, Celgene, AstraZeneca, Novartis, Pfizer, Zuckschwerdt Verlag 
GmbH, Georg Thieme Verlag, Aurikamed GmbH, MCI Deutschland $\mathrm{GmbH}$, bsh medical communications $\mathrm{GmbH}$ and promedicis $\mathrm{GmbH}$. W.J. received honoraria and research grants from Novartis, Roche, Pfizer, Lilly, AstraZeneca, Chugai, Sanofi, Daichi, Tesaro. F. S. participated on advisory boards for Novartis, Lilly, Amgen and Roche and received honoraria for lectures from Roche, AstraZeneca, MSD, Novartis and Pfizer. A. W. participated on advisory boards for Novartis, Lilly, Amgen, Pfizer, Roche, Tesaro, Eisai and received honoraria for lectures from Novartis, Pfizer, Aurikamed, Roche, Celgene. D. L. received honorarium from Amgen, AstraZeneca, Celgene, Lilly, Loreal, MSD, Novartis, Pfizer, Tesaro, Teva. T. N. F. has participated on advisory boards for Amgen, Daichi Sankyo, Novartis, Pfizer, and Roche and has received honoraria for lectures from Amgen, Celgene, Daichi Sankyo, Roche, Novartis and Pfizer.

\section{References}

[1] Brennan M, Gass P, Haberle L et al. The effect of participation in neoadjuvant clinical trials on outcomes in patients with early breast cancer. Breast Cancer Res Treat 2018. doi:10.1007/s10549-018-4829-4

[2] Hennigs A, Riedel F, Marme F et al. Changes in chemotherapy usage and outcome of early breast cancer patients in the last decade. Breast Cancer Res Treat 2016; 160: 491-499

[3] Kreienberg R, Wockel A, Wischnewsky M. Highly significant improvement in guideline adherence, relapse-free and overall survival in breast cancer patients when treated at certified breast cancer centres: An evaluation of 8323 patients. Breast 2018; 40: 54-59

[4] Beckmann MW, Brucker C, Hanf V et al. Quality assured health care in certified breast centers and improvement of the prognosis of breast cancer patients. Onkologie 2011; 34: 362-367

[5] Early Breast Cancer Trialists' Collaborative Group. Adjuvant bisphosphonate treatment in early breast cancer: meta-analyses of individual patient data from randomised trials. Lancet 2015; 386: 1353-1361

[6] Early Breast Cancer Trialists' Collaborative Group. Aromatase inhibitors versus tamoxifen in early breast cancer: patient-level meta-analysis of the randomised trials. Lancet 2015; 386: 1341-1352

[7] Early Breast Cancer Trialists' Collaborative Group (EBCTCG). Comparisons between different polychemotherapy regimens for early breast cancer: meta-analyses of long-term outcome among 100,000 women in 123 randomised trials. Lancet 2012; 379: 432-444

[8] Wunderle M, Olmes G, Nabieva N et al. Risk, Prediction and Prevention of Hereditary Breast Cancer - Large-Scale Genomic Studies in Times of Big and Smart Data. Geburtsh Frauenheilk 2018; 78: 481-492

[9] Fasching PA, Brucker SY, Fehm TN et al. Biomarkers in Patients with Metastatic Breast Cancer and the PRAEGNANT Study Network. Geburtsh Frauenheilk 2015; 75: 41-50

[10] Fasching PA, Ekici AB, Adamietz BR et al. Breast Cancer Risk - Genes, Environment and Clinics. Geburtsh Frauenheilk 2011; 71: 1056-1066

[11] Shimelis H, LaDuca H, Hu C et al. Triple-Negative Breast Cancer Risk Genes Identified by Multigene Hereditary Cancer Panel Testing. J Natl Cancer Inst 2018. doi:10.1093/jnci/djy106

[12] Couch FJ, Shimelis H, Hu C et al. Associations Between Cancer Predisposition Testing Panel Genes and Breast Cancer. JAMA Oncol 2017; 3: 1190-1196

[13] Kraus C, Hoyer J, Vasileiou $G$ et al. Gene panel sequencing in familial breast/ovarian cancer patients identifies multiple novel mutations also in genes others than BRCA1/2. Int J Cancer 2017; 140: 95-102

[14] Hauke J, Horvath J, Gross E et al. Gene panel testing of 5589 BRCA1/2negative index patients with breast cancer in a routine diagnostic setting: results of the German Consortium for Hereditary Breast and Ovarian Cancer. Cancer Med 2018; 7: 1349-1358
[15] Couch F], Hart SN, Sharma P et al. Inherited mutations in 17 breast cancer susceptibility genes among a large triple-negative breast cancer cohort unselected for family history of breast cancer. J Clin Oncol 2015; 33 : 304-311

[16] Fasching PA, Hu C, Hart SN et al. Cancer predisposition genes in metastatic breast cancer - Association with metastatic pattern, prognosis, patient and tumor characteristics [abstract]. In: Proceedings of the 2017 San Antonio Breast Cancer Symposium; 2017 Dec 5-9; San Antonio, TX Philadelphia (PA): AACR. Cancer Res 2018; 78: Abstr. PD1-02

[17] Hoyer J, Vasileiou G, Uebe $S$ et al. Addition of triple negativity of breast cancer as an indicator for germline mutations in predisposing genes increases sensitivity of clinical selection criteria. BMC Cancer 2018; 18: 926

[18] Antoniou AC, Casadei S, Heikkinen T et al. Breast-cancer risk in families with mutations in PALB2. N Engl J Med 2014; 371: 497-506

[19] Couch F], Hu C, Hart SN et al. Age-related breast cancer risk estimates for the general population based on sequencing of cancer predisposition genes in 19,228 breast cancer patients and 20,211 matched unaffected controls from US based cohorts in the CARRIERS study. San Antonio Breast Cancer Symposium 2018; Abstr. GS2-01

[20] Fasching PA, Schneeweiss A, Kolberg HC et al. Translational highlights in breast cancer research and treatment: recent developments with clinical impact. Curr Opin Obstet Gynecol 2019; 31: 67-75

[21] Ghoussaini M, Fletcher O, Michailidou K et al. Genome-wide association analysis identifies three new breast cancer susceptibility loci. Nat Genet 2012; 44: 312-318

[22] Garcia-Closas M, Couch F], Lindstrom S et al. Genome-wide association studies identify four ER negative-specific breast cancer risk loci. Nat Genet 2013; 45: 392-398, 398e1-398e2

[23] French JD, Ghoussaini M, Edwards SL et al. Functional variants at the 11 13 risk locus for breast cancer regulate cyclin D1 expression through long-range enhancers. Am J Hum Genet 2013; 92: 489-503

[24] Bojesen SE, Pooley KA, Johnatty SE et al. Multiple independent variants at the TERT locus are associated with telomere length and risks of breast and ovarian cancer. Nat Genet 2013; 45: 371-384, 384e1-384e2

[25] Michailidou K, Beesley J, Lindstrom S et al. Genome-wide association analysis of more than 120,000 individuals identifies 15 new susceptibility loci for breast cancer. Nat Genet 2015; 47: 373-380

[26] Michailidou K, Hall P, Gonzalez-Neira A et al. Large-scale genotyping identifies 41 new loci associated with breast cancer risk. Nat Genet 2013; 45: 353-361, 361e1-361e2

[27] Michailidou K, Lindstrom S, Dennis ] et al. Association analysis identifies 65 new breast cancer risk loci. Nature 2017; 551: 92-94

[28] Mavaddat N, Pharoah PD, Michailidou K et al. Prediction of breast cancer risk based on profiling with common genetic variants. J Natl Cancer Inst 2015; 107: pii: djv036

[29] Mavaddat N, Michailidou K, Dennis ] et al. Polygenic Risk Scores for Prediction of Breast Cancer and Breast Cancer Subtypes. Am J Hum Genet 2018. doi:10.1016/j.ajhg.2018.11.002

[30] Antoniou AC, Wang X, Fredericksen ZS et al. A locus on 19p13 modifies risk of breast cancer in BRCA1 mutation carriers and is associated with hormone receptor-negative breast cancer in the general population. Nat Genet 2010; 42: 885-892

[31] Haberle L, Hein A, Rubner M et al. Predicting Triple-Negative Breast Cancer Subtype Using Multiple Single Nucleotide Polymorphisms for Breast Cancer Risk and Several Variable Selection Methods. Geburtsh Frauenheilk 2017; 77: 667-678

[32] Haiman CA, Chen GK, Vachon CM et al. A common variant at the TERTCLPTM1 L locus is associated with estrogen receptor-negative breast cancer. Nat Genet 2011; 43: 1210-1214

[33] Milne RL, Benitez J, Nevanlinna $\mathrm{H}$ et al. Risk of estrogen receptor-positive and -negative breast cancer and single-nucleotide polymorphism 2q35rs13387042. J Natl Cancer Inst 2009; 101: 1012-1018 
[34] Milne RL, Kuchenbaecker KB, Michailidou K et al. Identification of ten variants associated with risk of estrogen-receptor-negative breast cancer. Nat Genet 2017; 49: 1767-1778

[35] Purrington KS, Slager S, Eccles D et al. Genome-wide association study identifies 25 known breast cancer susceptibility loci as risk factors for triple-negative breast cancer. Carcinogenesis 2014; 35: 1012-1019

[36] Stevens KN, Fredericksen Z, Vachon CM et al. 19p13.1 is a triple-negative-specific breast cancer susceptibility locus. Cancer Res 2012; 72: 1795-1803

[37] Stevens KN, Vachon CM, Lee AM et al. Common breast cancer susceptibility loci are associated with triple-negative breast cancer. Cancer Res 2011; 71: 6240-6249

[38] Broeks A, Schmidt MK, Sherman ME et al. Low penetrance breast cancer susceptibility loci are associated with specific breast tumor subtypes: findings from the Breast Cancer Association Consortium. Hum Mol Genet $2011 ; 20: 3289-3303$

[39] Figueroa JD, Garcia-Closas M, Humphreys M et al. Associations of common variants at 1 p11.2 and 14q24.1 (RAD51L1) with breast cancer risk and heterogeneity by tumor subtype: findings from the Breast Cancer Association Consortium. Hum Mol Genet 2011; 20: 4693-4706

[40] Yang XR, Chang-Claude J, Goode EL et al. Associations of breast cancer risk factors with tumor subtypes: a pooled analysis from the Breast Cancer Association Consortium studies. J Natl Cancer Inst 2011; 103: 250263

[41] Rudolph A, Song M, Brook MN et al. Joint associations of a polygenic risk score and environmental risk factors for breast cancer in the Breast Cancer Association Consortium. Int J Epidemiol 2018. doi:10.1093/ije/ dyx 242

[42] Vachon CM, Pankratz VS, Scott CG et al. The contributions of breast density and common genetic variation to breast cancer risk. J Natl Cancer Inst 2015; 107: pii: dju397

[43] Vachon CM, Scott CG, Fasching PA et al. Common breast cancer susceptibility variants in LSP1 and RAD51L1 are associated with mammographic density measures that predict breast cancer risk. Cancer Epidemiol Biomarkers Prev 2012; 21: 1156-1166

[44] Cutress RI, McIntosh SA, Potter S et al. Opportunities and priorities for breast surgical research. Lancet Oncol 2018; 19: e521-e533

[45] Kim HJ, Dominici L, Rosenberg S et al. Surgical treatment after neoadjuvant systemic therapy in young women with breast cancer: Results from a prospective cohort study. San Antonio Breast Cancer Symposium 2018; Abstr. GS6-01

[46] Rosenberg SM, O'Neill A, Sepucha K et al. The impact of breast cancer surgery on quality of life: Long term results from E5103. San Antonio Breast Cancer Symposium 2018; Abstr. GS6-05

[47] Dominici LS, Hu J, King TA et al. Local therapy and quality of life outcomes in young women with breast cancer. San Antonio Breast Cancer Symposium 2018; Abstr. GS6-06

[48] Bani MR, Beckmann K, Engel J et al. Correlates of the desire for improved cosmetic results after breast-conserving therapy and mastectomy in breast cancer patients. Breast 2008; 17: 640-645

[49] Kuehn T, Bauerfeind I, Fehm T et al. Sentinel-lymph-node biopsy in patients with breast cancer before and after neoadjuvant chemotherapy (SENTINA): a prospective, multicentre cohort study. Lancet Oncol 2013; 14: 609-618

[50] Kolberg HC, Liedtke C, Bauerfeind I et al. Residual axillary involvement in early breast cancer in patients with positive sentinel nodes after neoadjuvant chemotherapy (NACT). San Antonio Breast Cancer Symposium 2018; Abstr. PD8-02

[51] Liedtke C, Kolberg HC, Kerschke L et al. Systematic analysis of parameters predicting pathological axillary status (ypN0 vs. ypN+) in patients with breast cancer converting from $\mathrm{CN}+$ to ycN0 through primary systemic therapy (PST). Clin Exp Metastasis 2018; 35: 777-783
[52] Giuliano AE, Hunt KK, Ballman KV et al. Axillary dissection vs. no axillary dissection in women with invasive breast cancer and sentinel node metastasis: a randomized clinical trial. JAMA 2011; 305: 569-575

[53] Rutgers E], Donker M, Poncet $C$ et al. Radiotherapy or surgery of the axilla after a positive sentinel node in breast cancer patients: 10 year follow up results of the EORTC AMAROS trial (EORTC10981/22023). San Antonio Breast Cancer Symposium 2018; Abstr. GS4-01

[54] Vicini FA, Cecchini RS, White JR et al. Primary results of NSABP B-39/ RTOG 0413 (NRG Oncology): A randomized phase III study of conventional whole breast irradiation (WBI) versus partial breast irradiation (PBI) for women with stage 0, I, or II breast cancer. San Antonio Breast Cancer Symposium 2018; Abstr. GS4-02

[55] Kommission Mamma der Arbeitsgemeinschaft Gynäkologische Onkologie e.V. in der Deutschen Gesellschaft für Gynäkologie und Geburtshilfe e.V. sowie in der Deutschen Krebsgesellschaft e.V. Diagnostik und Therapie von Patientinnen mit primärem und metastasiertem Brustkrebs. Online: https://wwwago-onlinede/fileadmin/downloads/leitlinien/ mamma/2017-03/AGO_deutsch/PDF_Gesamtdatei_deutsch/Alle_ aktuellen_Empfehlungen_2018pdf 2018; last access: 07.07.2018

[56] Wockel A, Festl ], Stuber T et al. Interdisciplinary Screening, Diagnosis, Therapy and Follow-up of Breast Cancer. Guideline of the DGGG and the DKG (S3-Level, AWMF Registry Number 032/045OL, December 2017) - Part 2 with Recommendations for the Therapy of Primary, Recurrent and Advanced Breast Cancer. Geburtsh Frauenheilk 2018; 78: 1056-1088

[57] Wockel A, Festl J, Stuber T et al. Interdisciplinary Screening, Diagnosis, Therapy and Follow-up of Breast Cancer. Guideline of the DGGG and the DKG (S3-Level, AWMF Registry Number 032/045OL, December 2017) - Part 1 with Recommendations for the Screening, Diagnosis and Therapy of Breast Cancer. Geburtsh Frauenheilk 2018; 78: 927-948

[58] Dodwell D, Taylor C, McGale P et al. Regional lymph node irradiation in early stage breast cancer: An EBCTCG meta-analysis of 13,000 women in 14 trials. San Antonio Breast Cancer Symposium 2018; Abstr. GS4-02

[59] Cortazar P, Geyer CE jr. Pathological complete response in neoadjuvant treatment of breast cancer. Ann Surg Oncol 2015; 22: 1441-1446

[60] Fasching PA, Heusinger K, Haeberle L et al. Ki67, chemotherapy response, and prognosis in breast cancer patients receiving neoadjuvant treatment. BMC Cancer 2011; 11: 486

[61] Fasching PA, Loibl S, Hu C et al. BRCA1/2 Mutations and Bevacizumab in the Neoadjuvant Treatment of Breast Cancer: Response and Prognosis Results in Patients With Triple-Negative Breast Cancer From the GeparQuinto Study. J Clin Oncol 2018. doi:10.1200/JCO.2017.77.2285

[62] von Minckwitz G, Untch M, Blohmer JU et al. Definition and impact of pathologic complete response on prognosis after neoadjuvant chemotherapy in various intrinsic breast cancer subtypes. J Clin Oncol 2012; 30: 1796-1804

[63] Wunderle M, Gass P, Haberle L et al. BRCA mutations and their influence on pathological complete response and prognosis in a clinical cohort of neoadjuvantly treated breast cancer patients. Breast Cancer Res Treat 2018; 171: 85-94

[64] Untch M, Fasching PA, Konecny GE et al. Pathologic complete response after neoadjuvant chemotherapy plus trastuzumab predicts favorable survival in human epidermal growth factor receptor 2-overexpressing breast cancer: results from the TECHNO trial of the AGO and GBG study groups. J Clin Oncol 2011; 29: 3351-3357

[65] Untch M, von Minckwitz G, Konecny GE et al. PREPARE trial: a randomized phase III trial comparing preoperative, dose-dense, dose-intensified chemotherapy with epirubicin, paclitaxel, and CMF versus a standarddosed epirubicin-cyclophosphamide followed by paclitaxel with or without darbepoetin alfa in primary breast cancer-outcome on prognosis. Ann Oncol 2011; 22: 1999-2006 
[66] Untch M, Fasching PA, Konecny GE et al. PREPARE trial: a randomized phase III trial comparing preoperative, dose-dense, dose-intensified chemotherapy with epirubicin, paclitaxel and CMF versus a standard-dosed epirubicin/cyclophosphamide followed by paclitaxel \pm darbepoetin alfa in primary breast cancer-results at the time of surgery. Ann Oncol 2011; 22: 1988-1998

[67] Masuda N, Lee S], Ohtani S et al. Adjuvant Capecitabine for Breast Cancer after Preoperative Chemotherapy. N Engl J Med 2017; 376: 2147-2159

[68] Adams S, Loi S, Toppmeyer DL et al. KEYNOTE-086 cohort B: Pembrolizumab monotherapy for PD-L1-positive, previously untreated, metastatic triple-negative breast cancer (mTNBC) [abstract]. In: Proceedings of the 2017 San Antonio Breast Cancer Symposium; 2017 Dec 5-9; San Antonio, TX Philadelphia (PA): AACR. Cancer Res 2018; 78: Abstr. PF6-10

[69] Martín M, Barrios CH, Torrecillas L et al. Efficacy results from CIBOMA/ 2004-01_GEICAM/2003-11 study: A randomized phase III trial assessing adjuvant capecitabine after standard chemotherapy for patients with early triple negative breast cancer. San Antonio Breast Cancer Symposium 2018; Abstr. GS2-04

[70] Gass P, Lux MP, Rauh C et al. Prediction of pathological complete response and prognosis in patients with neoadjuvant treatment for triplenegative breast cancer. BMC Cancer 2018; 18: 1051

[71] von Minckwitz G, Schneeweiss A, Loibl S et al. Neoadjuvant carboplatin in patients with triple-negative and HER2-positive early breast cancer (GeparSixto; GBG 66): a randomised phase 2 trial. Lancet Oncol 2014; 15: 747-756

[72] Loibl S, Weber KE, Timms KM et al. Survival analysis of carboplatin added to an anthracycline/taxane-based neoadjuvant chemotherapy and HRD score as predictor of response - final results from GeparSixto. Ann Oncol 2018. doi:10.1093/annonc/mdy460

[73] Wardley AM, Hiller L, Howard HC et al. tAnGo: a randomised phase III trial of gemcitabine in paclitaxel-containing, epirubicin/cyclophosphamide-based, adjuvant chemotherapy for early breast cancer: a prospective pulmonary, cardiac and hepatic function evaluation. $\mathrm{Br}$ J Cancer 2008; 99: 597-603

[74] Swain SM, Tang G, Geyer CE jr. et al. Definitive results of a phase III adjuvant trial comparing three chemotherapy regimens in women with operable, node-positive breast cancer: the NSABP B-38 trial. J Clin Oncol 2013; 31: 3197-3204

[75] Earl HM, Vallier AL, Hiller L et al. Effects of the addition of gemcitabine, and paclitaxel-first sequencing, in neoadjuvant sequential epirubicin, cyclophosphamide, and paclitaxel for women with high-risk early breast cancer (Neo-tAnGo): an open-label, 2×2 factorial randomised phase 3 trial. Lancet Oncol 2014; 15: 201-212

[76] Bear HD, Tang G, Rastogi $P$ et al. Bevacizumab added to neoadjuvant chemotherapy for breast cancer. N Engl J Med 2012; 366: 310-320

[77] Bear HD, Tang G, Rastogi P et al. Neoadjuvant plus adjuvant bevacizumab in early breast cancer (NSABP B-40 [NRG Oncology]): secondary outcomes of a phase 3, randomised controlled trial. Lancet Oncol 2015; 16: $1037-1048$

[78] von Minckwitz G, Timms K, Untch M et al. Homologous repair deficiency (HRD) as measure to predict the effect of carboplatin on survival in the neoadjuvant phase II trial GeparSixto in triple-negative early breast cancer. Cancer Res 2017; 77: Abstr. P1-09-02

[79] Hahnen E, Lederer B, Hauke J et al. Germline Mutation Status, Pathological Complete Response, and Disease-Free Survival in Triple-Negative Breast Cancer: Secondary Analysis of the GeparSixto Randomized Clinical Trial. JAMA Oncol 2017; 3: 1378-1385

[80] Untch M, Jackisch C, Schneeweiss A et al. Nab-paclitaxel versus solventbased paclitaxel in neoadjuvant chemotherapy for early breast cancer (GeparSepto-GBG 69): a randomised, phase 3 trial. Lancet Oncol 2016; 17: $345-356$
[81] Schneeweiss A, Jackisch C, Schmatloch S et al. Survival analysis of the prospectively randomized phase III GeparSepto trial comparing neoadjuvant chemotherapy with weekly nab-paclitaxel with solvent-based paclitaxel followed by anthracycline-cyclosphosphamide for patients with early breast cancer - GBG69 [abstract]. In: Proceedings of the 2017 San Antonio Breast Cancer Symposium; 2017 Dec 5-9; San Antonio, TX Philadelphia (PA): AACR. Cancer Res 2018; 78: Abstr. GS3-05

[82] Gluz O, Nitz U, Liedtke C et al. Comparison of Neoadjuvant Nab-Paclitaxel+Carboplatin vs. Nab-Paclitaxel+Gemcitabine in Triple-Negative Breast Cancer: Randomized WSG-ADAPT-TN Trial Results. J Natl Cancer Inst 2018; 110: 628-637

[83] Gluz O, Nitz U, Liedtke C et al. Impact of 12 weeks nab-paclitaxel + carboplatin or gemcitabine followed by anthracycline administration according to PCR in triple-negative early breast cancer: Survival results of WSG-ADAPT-TN phase II trial. J Clin Oncol 2018; 36 (Suppl): Abstr. 573

[84] Gluz O, Nitz U, Liedtke C et al. No survival benefit of chemotherapy escalation in patients with $\mathrm{pCR}$ and high-immune triple-negative early breast cancer in the neoadjuvant WSG-ADAPT-TN trial. San Antonio Breast Cancer Symposium 2018; Abstr. GS5-06

[85] Cortazar P, Zhang L, Untch M et al. Pathological complete response and long-term clinical benefit in breast cancer: the CTNeoBC pooled analysis. Lancet 2014; 384: 164-172

[86] Sparano JA, Gray RJ, Makower DF et al. Adjuvant Chemotherapy Guided by a 21-Gene Expression Assay in Breast Cancer. N Engl J Med 2018; 379 : $111-121$

[87] Wagner LI, Gray RJ, Garcia S et al. Symptoms and health-related quality of life on endocrine therapy alone (E) versus chemoendocrine therapy $(\mathrm{C}+\mathrm{E})$ : TAILORx patient-reported outcomes results. San Antonio Breast Cancer Symposium 2018; Abstr. GS6-03

[88] Janni W, Schneeweiss A, Müller V et al. Update Breast Cancer 2019 Part 2 - Implementation of Novel Diagnostics and Therapeutics in Advanced Breast Cancer Patients in Clinical Practice. Geburtsh Frauenheilk 2019; 268-280

[89] Early Breast Cancer Trialists' Collaborative Group. Effects of prolonging adjuvant aromatase inhibitor therapy beyond five years on recurrence and cause-specific mortality: An EBCTCG meta-analysis of individual patient data from 12 randomised trials including 24,912 women. San Antonio Breast Cancer Symposium 2018; Abstr. GS3-03

[90] Ohtani S, lijima K, Higaki K et al. A prospective randomized multi-center open-label phase III trial of extending aromatase-inhibitor adjuvant therapy to 10 years - Results from 1697 postmenopausal women in the N-SAS BC05 trial: Arimidex extended adjuvant randomized study (AERAS). San Antonio Breast Cancer Symposium 2018; Abstr. GS3-04

[91] Baselga J, Campone M, Piccart M et al. Everolimus in postmenopausal hormone-receptor-positive advanced breast cancer. N Engl J Med 2012; 366: 520-529

[92] Tesch H, Stoetzer O, Decker T et al. Efficacy and safety of everolimus plus exemestane in postmenopausal women with hormone receptor-positive, human epidermal growth factor receptor 2-negative locally advanced or metastatic breast cancer: Results of the single-arm, phase IIIB 4EVER trial. Int J Cancer 2019; 144: 877-885

[93] Dowsett M, Jacobs S, Johnston S et al. PALLET: A neoadjuvant study to compare the clinical and antiproliferative effects of letrozole with and without palbociclib. San Antonio Breast Cancer Symposium 2018; Abstr. GS3-02

[94] Hadji P, Blettner M, Harbeck N et al. The Patient's Anastrozole Compliance to Therapy (PACT) Program: a randomized, in-practice study on the impact of a standardized information program on persistence and compliance to adjuvant endocrine therapy in postmenopausal women with early breast cancer. Ann Oncol 2013; 24: 1505-1512

[95] Hadji P, Jackisch C, Bolten W et al. COMPliance and Arthralgia in Clinical Therapy: the COMPACT trial, assessing the incidence of arthralgia, and compliance within the first year of adjuvant anastrozole therapy. Ann Oncol 2014; 25: 372-377 
[96] Hadji P, Ziller V, Kyvernitakis J et al. Persistence in patients with breast cancer treated with tamoxifen or aromatase inhibitors: a retrospective database analysis. Breast Cancer Res Treat 2013; 138: 185-191

[97] Nabieva N, Fehm T, Haberle L et al. Influence of side-effects on early therapy persistence with letrozole in post-menopausal patients with early breast cancer: Results of the prospective EvAluate-TM study. Eur J Cancer 2018; 96: 82-90

[98] Nabieva N, Kellner S, Fehm T et al. Influence of patient and tumor characteristics on early therapy persistence with letrozole in postmenopausal women with early breast cancer: results of the prospective Evaluate-TM study with 3941 patients. Ann Oncol 2018; 29: 186-192

[99] Fernandez-Gonzalez S, Falo C, Pla MJ et al. The Shift From Sentinel Lymph Node Biopsy Performed Either Before or After Neoadjuvant Systemic Therapy in the Clinical Negative Nodes of Breast Cancer Patients. Results, and the Advantages and Disadvantages of Both Procedures. Clin Breast Cancer 2018; 18: 71-77

[100] Fasching PA, Gass P, Hein A. Neoadjuvant Treatment of Breast Cancer Advances and Limitations. Breast Care (Basel) 2016; 11: 313-314

[101] Robertson JFR, Dowsett M, Bliss JM et al. Peri-operative Aromatase Inhibitor treatment in determining or predicting Longterm Outcome in Early Breast Cancer - the POETIC* Trial (CRUK/07/015) [abstract]. In: Proceedings of the 2017 San Antonio Breast Cancer Symposium; 2017 Dec 5-9; San Antonio, TX Philadelphia (PA): AACR. Cancer Res 2018; 78: Abstr. GS1-03
[102] Spring LM, Fell G, Arfe A et al. Pathological complete response after neoadjuvant chemotherapy and impact on breast cancer recurrence and mortality, stratified by breast cancer subtypes and adjuvant chemotherapy usage: Individual patient-level meta-analyses of over 27,000 patients. San Antonio Breast Cancer Symposium 2018; Abstr. GS2-03

[103] von Minckwitz G, Huang CS, Mano MS et al. Trastuzumab Emtansine for Residual Invasive HER2-Positive Breast Cancer. N Engl J Med 2018. doi:10.1056/NEJMoa1814017

[104] Geyer CE jr., Huang CS, Mano MS et al. Phase III study of trastuzumab emtansine (T-DM1) vs. trastuzumab as adjuvant therapy in patients with HER2-positive early breast cancer with residual invasive disease after neoadjuvant chemotherapy and HER2-targeted therapy including trastuzumab: Primary results from KATHERINE. San Antonio Breast Cancer Symposium 2018; Abstr. GS1-10

[105] Fasching PA, Hartkopf AD, Gass P et al. Efficacy of neoadjuvant pertuzumab in addition to chemotherapy and trastuzumab in routine clinical treatment of patients with primary breast cancer: a multicentric analysis. Breast Cancer Res Treat 2018. doi:10.1007/s10549-0185008-3

[106] Refae S, Pistilli B, Delaloge S. Extended anti-HER2 therapy in early breast cancer: longer beats shorter? Curr Opin Oncol 2016; 28: 469475

[107] Pivot X, Romieu G, Debled M et al. PHARE randomized trial final results comparing 6 to 12 months of trastuzumab in adjuvant early breast cancer. San Antonio Breast Cancer Symposium 2018; Abstr. GS2-07 